\title{
COMPARISON OF BEHAVIORAL ASPECTS OF HIGH RISE MULTISTORIED STEEL BUILDING WITH MASS PENDULUM SYSTEM AND X- BRACING SYSTEM USING STAAD.PRO V8I SOFTWARE
}

\author{
Jemal Bedane Halkiyo ${ }^{1}$, Sultan Bedane Halkiyu², Raju Ramesh Reddy ${ }^{3}$ \\ ${ }^{1}$ Lecturer, Civil Engineering Department, Bule Hora University, Bule Hora, Ethiopia \\ ${ }^{2}$ Lecturer, Civil Engineering Department, Bule Hora University, Bule Hora, Ethiopia \\ ${ }^{3}$ Professor, Civil Engineering Department, Arba Minch University, Ethiopia
}

\begin{abstract}
High Rise Multistory steel building developments have been rapidly increasing throughout our Country and worldwide. The lateral deflections of buildings includes bending and shear deflection are challenging part to the designed and existed building. Previously the X-bracing system is more effective to control the deflection of the high rise steel building. In this research, the new system called Mass pendulum Mechanism is introduced to control the lateral deflection of the steel building and the same compared with the X-bracing system. Mass pendulum system which is proved to be the better deflection controlling system is studied in depth and the overall comparison of the system with other deflection controlling mechanisms is outlined and analyzed. The use of this mechanism for design of high rise steel building can increase the lateral stiffness of building and decrease lateral displacements. The maximum reduction in the lateral displacement occurs at an angle of mass 45 degree with the weight of mass equal to $50 \%$ of the lateral load. In addition the Mass Pendulum Mechanism reduces bending moments and shear forces in the vertical and horizontal members of load transferring system. Moreover, stability of this system increases and the P-Delta effects decline. So, the columns will be protected against reaching nonlinear state. Finally the mass Pendulum system proved that it's economical compare with $X$-bracing system in terms of structural steel material.
\end{abstract}

Keywords: High-rise steel building, X-bracing system, Mass-pendulum mechanism, Deflection, Lateral deflection, lateral stiffness and Plate stress

Abbreviations:- XBS:-X-Bracing System, e-Eccentricity, M-self weight of building, MPS-30 DEGREE- Mass pendulum system at 30 degree, MPS-45 DEGREE- Mass pendulum system at 45 degree, MPS-60 DEGREE- Mass pendulum system at 60 degree.

\section{INTRODUCTION}

The introduction of structural steel to building construction in the late 19th and early 20th centuries, Engineers have recognized that steel building and structures have performed extremely well compared with structures of other types of construction. The selection of structural steel for a building's framing system brings numerous benefits to a project. Speed of Construction, sustainability, strength and aesthetic, efficient design flexibility are some advantage of steel structure.

Comparatively high rise multi story steel buildings are light in weight which makes steel structure very susceptible to lateral load. Engineers overcome the deflection in multistorey steel building by providing bracing. Steel braced frame is one of the structural system used to resist lateral loads in multi-storeyed buildings. $\mathrm{X}$-bracing is more effective system of controlling deflection than the other bracing system. Even though this system controls the deflection of the building caused by the lateral loads, one needs a large quantity material used as a bracing element.

Generally, in multistorey steel building, there may be high deflection due to relative light weight of steel to that of concrete and the height of the building. Many researchers steel bracing is a high efficient and economical method of resisting horizontal forces in a frame structure. Bracing has been used to stabilize lateral for the majority of the world's tallest building structures. Bracing is efficient because the diagonals work in axial stress and therefore call for minimum member sizes in providing stiffness and strength against horizontal shear. The effectiveness of varies types of steel bracing on the structure has also been investigated. More importantly, the reduction in lateral displacement has been found out for different types of bracing system in 
comparison to building with no bracing. From the present studying, it has been found that the mass pendulum reduces more lateral displacement and X-bracing system significantly contributes to greater structural stiffness to the structure.

\section{OBJECTIVES}

- To Compare vertical deflection of high rise multistoried steel building with a new technique (mass pendulum system) with old system(X-bracing system)

- To Compare the overall effectiveness and plate stress of high- rise steel building with both methods

\section{METHODOLOGY}

In the study, STAAD PRO V8i software is used to model and analyze the data. By using this software, the properties of the members are assigned. The structure is later analyzed to evaluate vertical deflections and overall effectiveness and plate stresses of high rise steel building.

The general data for the frame is as follows:-

\subsection{Specimens}

This research is studied using three specimens. The specimens are compared with the control building modelled using old system (x-bracing).

Table - 1: Specimen

\begin{tabular}{|l|l|l|}
\hline Serial no & $\begin{array}{l}\text { Types of } \\
\text { Specimen }\end{array}$ & Description \\
\hline 1 & Case 1 & $\begin{array}{l}\text { Control building } \\
\text { (x-bracing) }\end{array}$ \\
\hline 2 & Case 2 & $\begin{array}{l}\text { Mass pendulum } \\
\text { System }\left(30^{0}\right)\end{array}$ \\
\hline 3 & Case 3 & $\begin{array}{l}\text { Mass pendulum } \\
\text { System }\left(45^{0}\right)\end{array}$ \\
\hline 4 & Case 4 & $\begin{array}{l}\text { Mass pendulum } \\
\text { System }\left(60^{\circ}\right)\end{array}$ \\
\hline
\end{tabular}

The building is:-

- A high rise multistory steel building and symmetrical in plan and elevation.

- Has 25 typical floors

The different stages used in the simple Mass pendulum of high-rise steel building

\subsubsection{Case one}

In case 1 we used: - single channel section X- Bracing

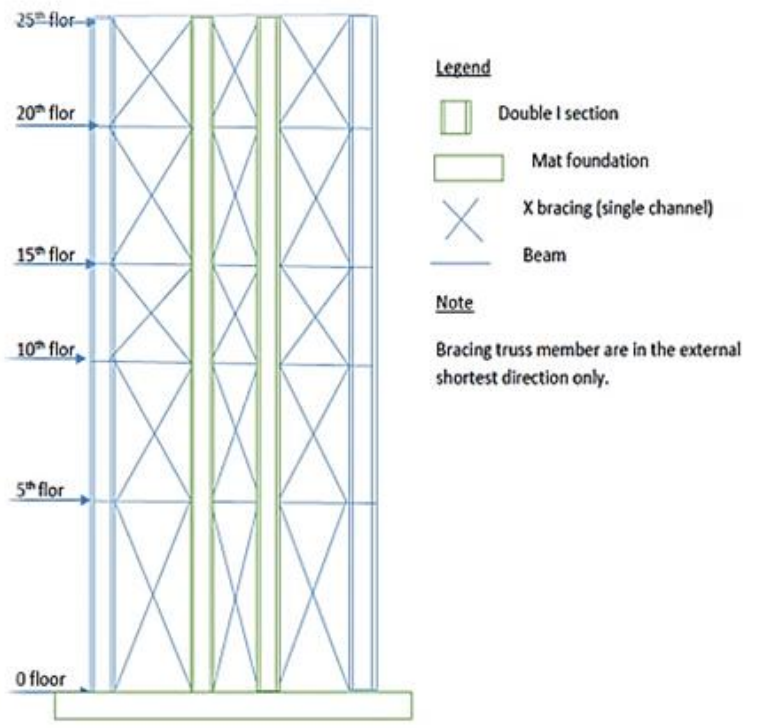

Fig: 1 Model for case 1

\subsubsection{Case Two}

In case two we used:

- The weight of pendulum is $50 \%$ of the wind load in the Z-direction

- The angle of swing is 30 degree

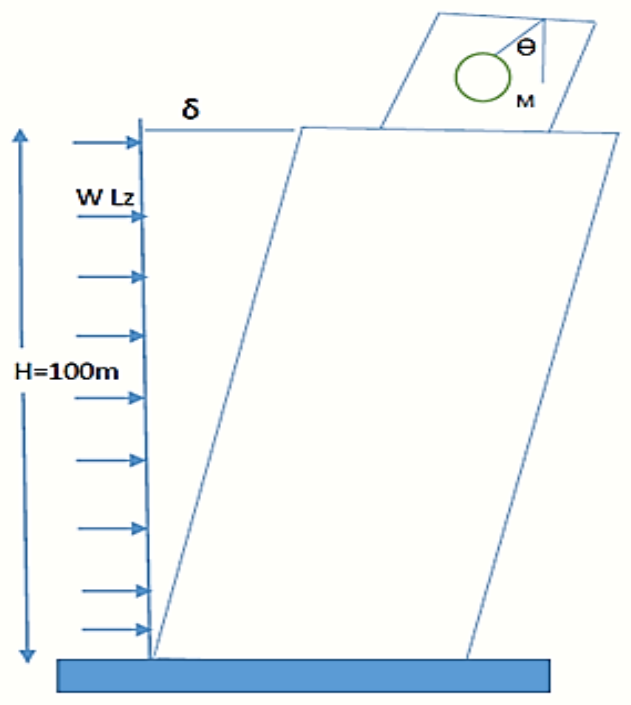

Fig: 2_Model for case 2

\subsubsection{Case Three}

In case three we used:

- The weight of the pendulum is $50 \%$ of the wind load in the Z-direction

- The angle of swing is 45 degree. 


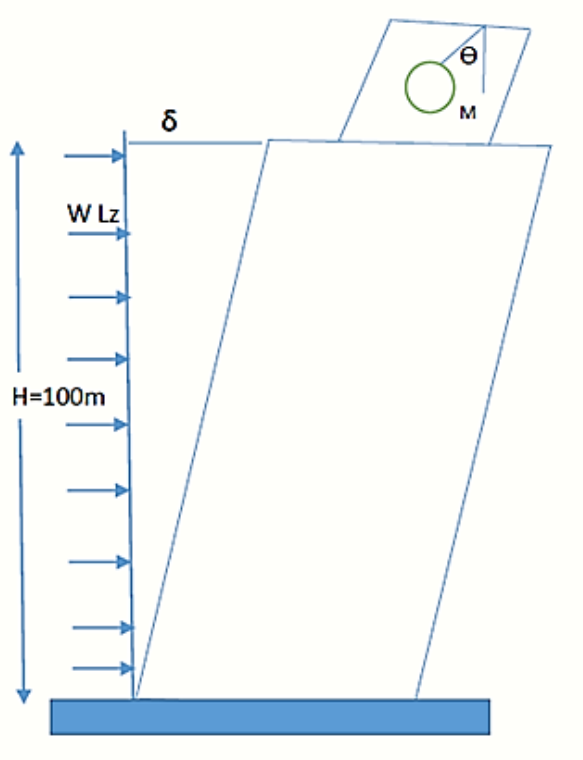

Fig: 3 Model for case 3

\subsubsection{Case Four}

In case four we used:

- The weight of the pendulum is $50 \%$ of the wind load in the Z-direction

- The angle of swing is 60 degree

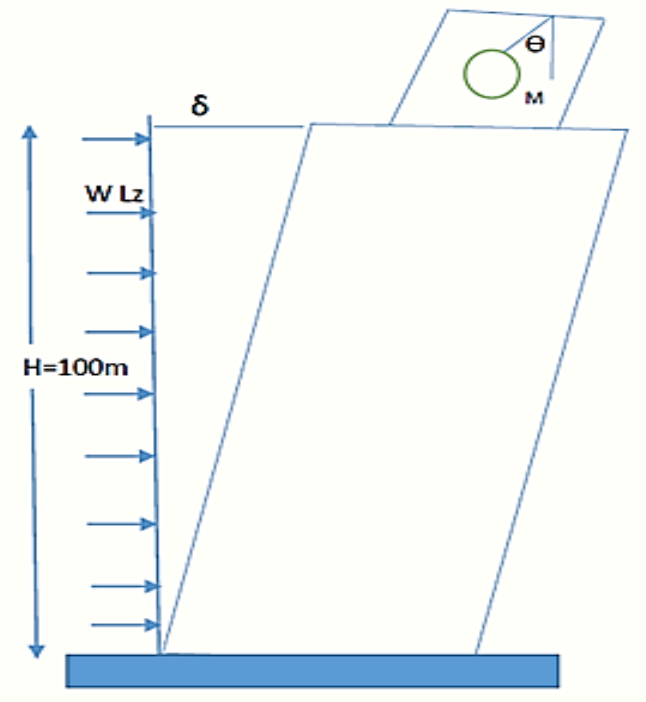

Fig: 4_Model for case 4

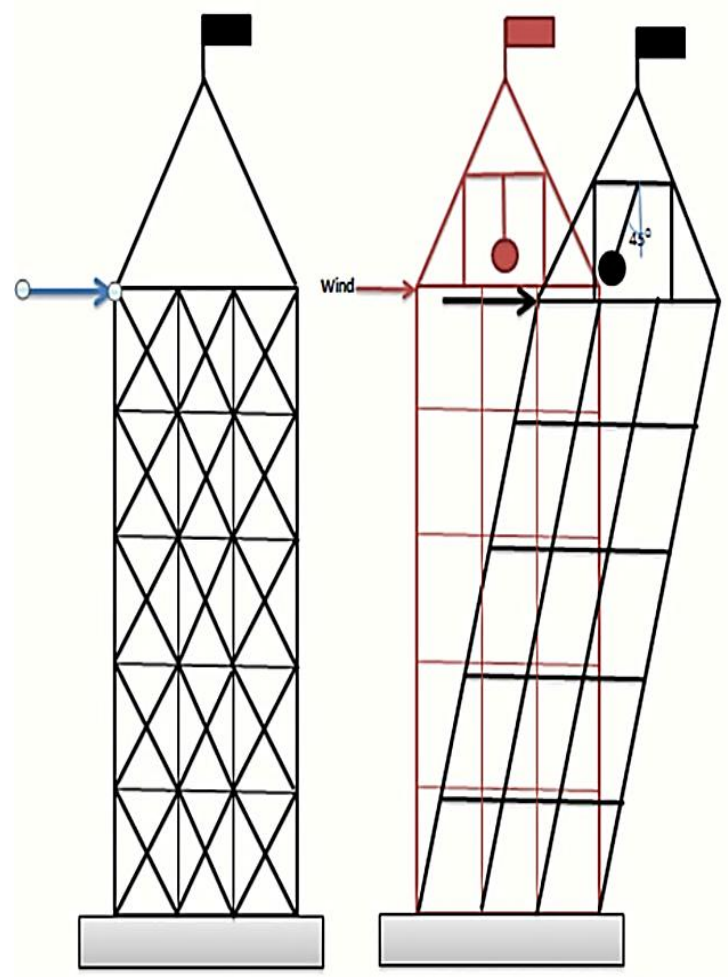

Fig: 5_Models

\subsection{Data Considered for Model}

- Building Function: Commercial shopping

- Terrain: Category :IV

- No. of Floor: 25

- Floor Height: 4m typical

- Regularity in plan : Symmetry about both axes

- Floor Plan: Typical all floors

- Type Of Floor: Solid slab

- Structural System: Moment resisting frame

- Assumed depth of foundation: $4 \mathrm{~m}$ from ground level

- Software: STAAD Pro.v8i

- Design Code: Ethiopian Building Code of StandardEBCS Code

\subsection{Material Property}

- Material used: structural steel

- Modules of elasticity $=205 \mathrm{kN} / \mathrm{mm} 2$

- Yield strength (py) $=550 \mathrm{~N} / \mathrm{mm} 2$

- Ultimate strength (fu) $=600 \mathrm{~N} / \mathrm{mm} 2$

- Net area $=85 \%$ of cross sectional area.

- Grade of steel reinforcement (raft foundation): S-400

- Grade of concrete (raft foundation): C-30

\subsection{Loading Details}

- $\quad$ Dead Load (DL) $=4.5 \mathrm{KN} / \mathrm{M} 2$

- Dead Load From Wall = 4KN/M2

- $\quad$ Back Fill = 45KN/M2

- $\quad$ Live Load (LL) = 5KN/M2 [EBCS-1-1995]

- $\quad$ LL At The Top Story = 1.5KN/M2

- $\quad$ Min Wind Pressure $=1.53$ KN/M2

- $\quad$ Max Wind Pressure $=2.97$ KN/M2 


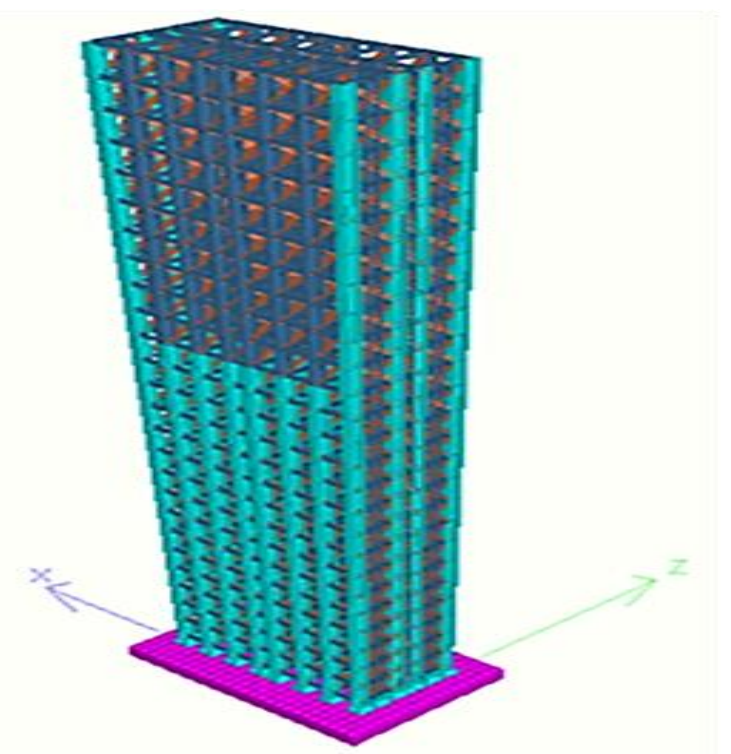

Fig: 6-_BD Dimensional rendered view of building

\section{ANALYSIS, RESULTS AND DISCUSSION}

The different behavioral aspects of high rise multistory building is analyzed for four cases with MPS system and XBracing system and the results are as given below:

\subsection{Quantity Comparison}

The Structural steel, reinforcement steel and reinforced concrete quantity variation for the four cases as mentioned in Table 1 is compared and the results are presented in the graphs as shown below.

\section{SUBSTRUCTURE-STEEL REINFOR. QTY [MT]}

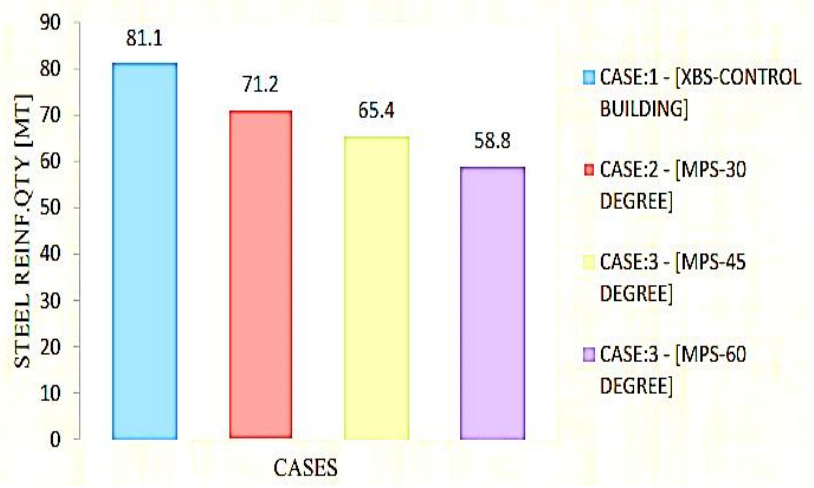

SUPERSTRUCTURE-STRUCTURAL STEEL QTY [MT]

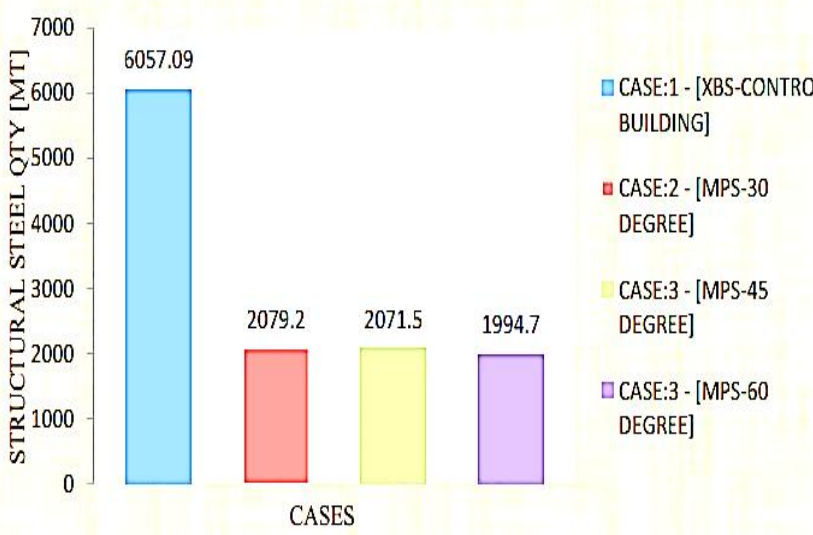

SUBSTRUCTURE-CONCRETE QTY [M3]

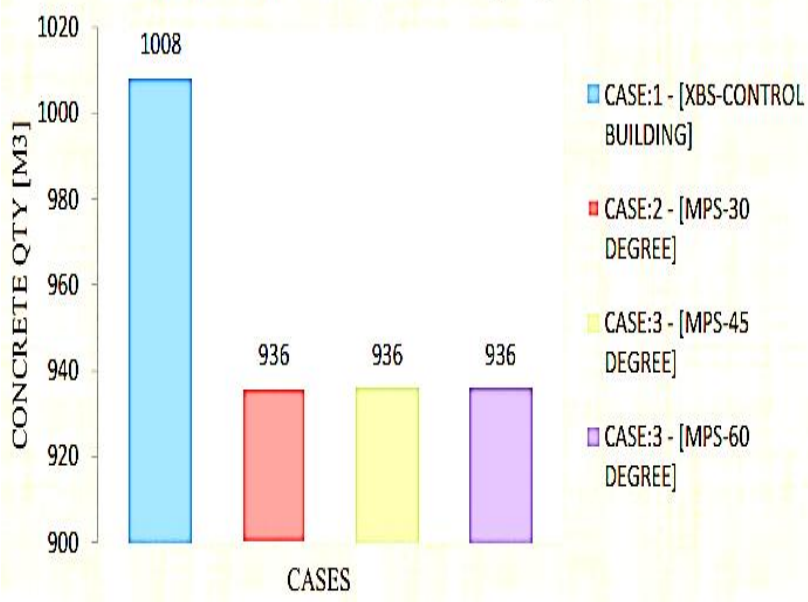

Fig: 8_Quantity comparisons

As shown on quantity comparison diagrams above; structural steel, reinforced steel and reinforced concrete quantity required for case:3-[MPS-60] is lower as compared to other cases of XBS-Control building and mass pendulum bracing systems at different angles. 


\section{PERCENTAGE VARIATION OF MATERIALQTY. W.R.T CASE 1}

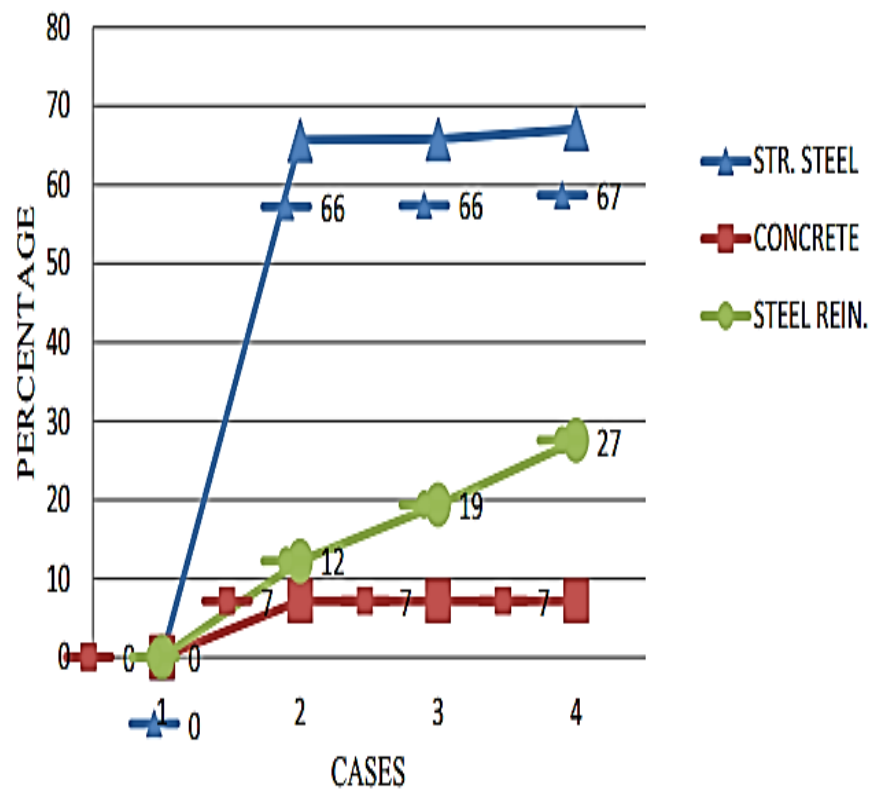

Fig: 9_Percentage variation of material quantity

\subsection{Bending Behavior}

In the design and analysis of building, the bending behavior of four cases are studied in depth. The result shows that the bending behavior of building is more with XBS for case 1 , where as the bending behavior of mass pendulum is less for cases 2 to 4 as shown in the figure 10 .

\section{BENDING BEHAVIOR}

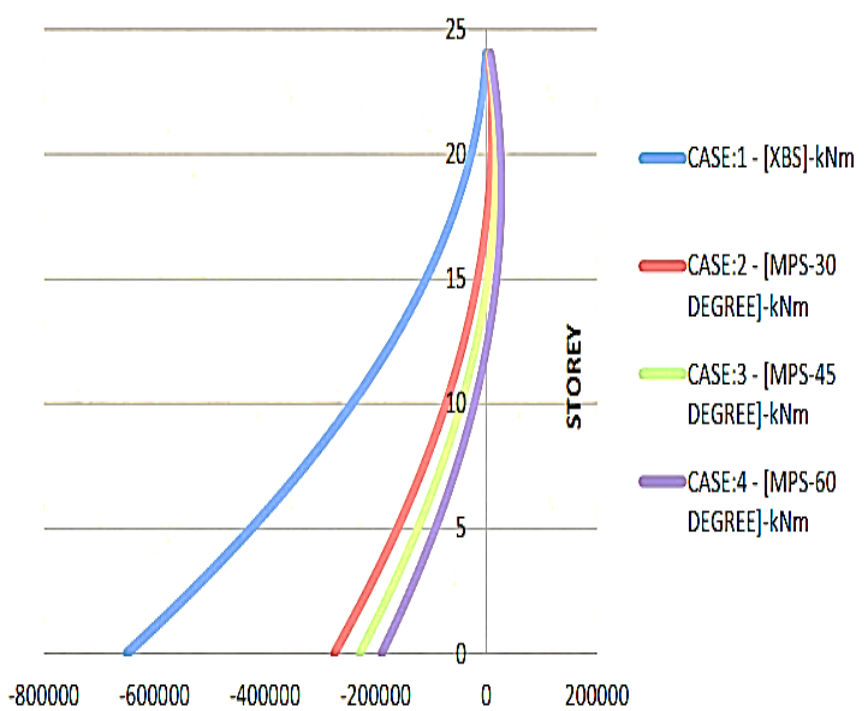

TRANSVERSE MOMENT VALUES [KN-M]

Fig: 10_Bending behavior

\subsection{Transverse Shear Behavior}

The analysis and design of the multi-story building has extended by comparing the transverse shear behavior by two methods for all the four cases. The results indicates that the transverse shear behavior is maximum for case 1 with XBS system as compared to MPS system for cases 2 to 4 as shown in the figure 11 .

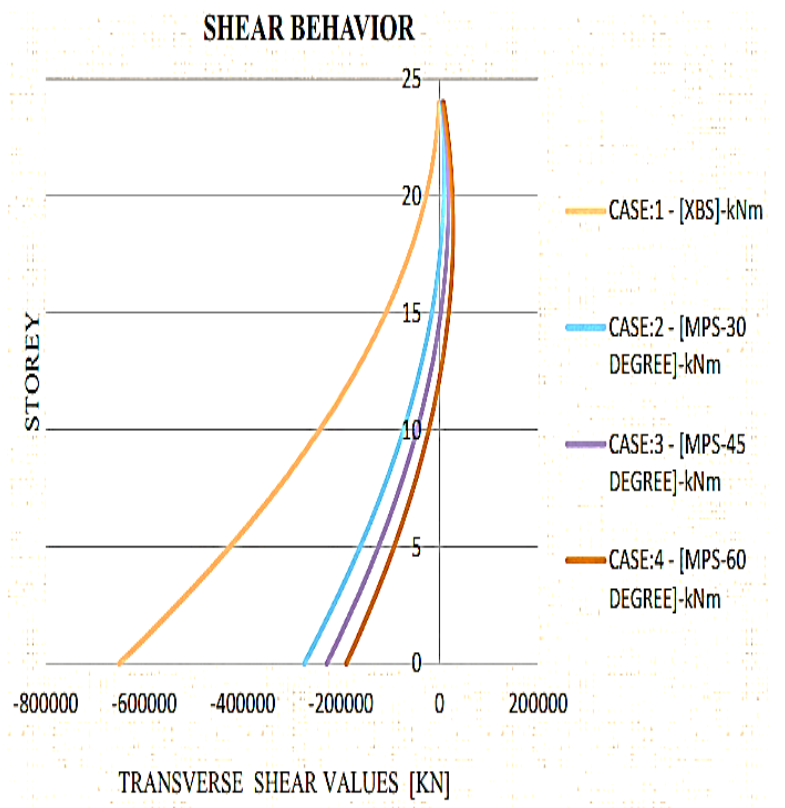

Fig: 11 Shear Behavior

\subsection{Base Pressure}

In the analysis, base pressure is also compared for all the four cases with both the methods. The results shows that the base pressure is maximum for case 1 with XBS system and it is minimal for other cases with MPS system as shown in the figure 12 .

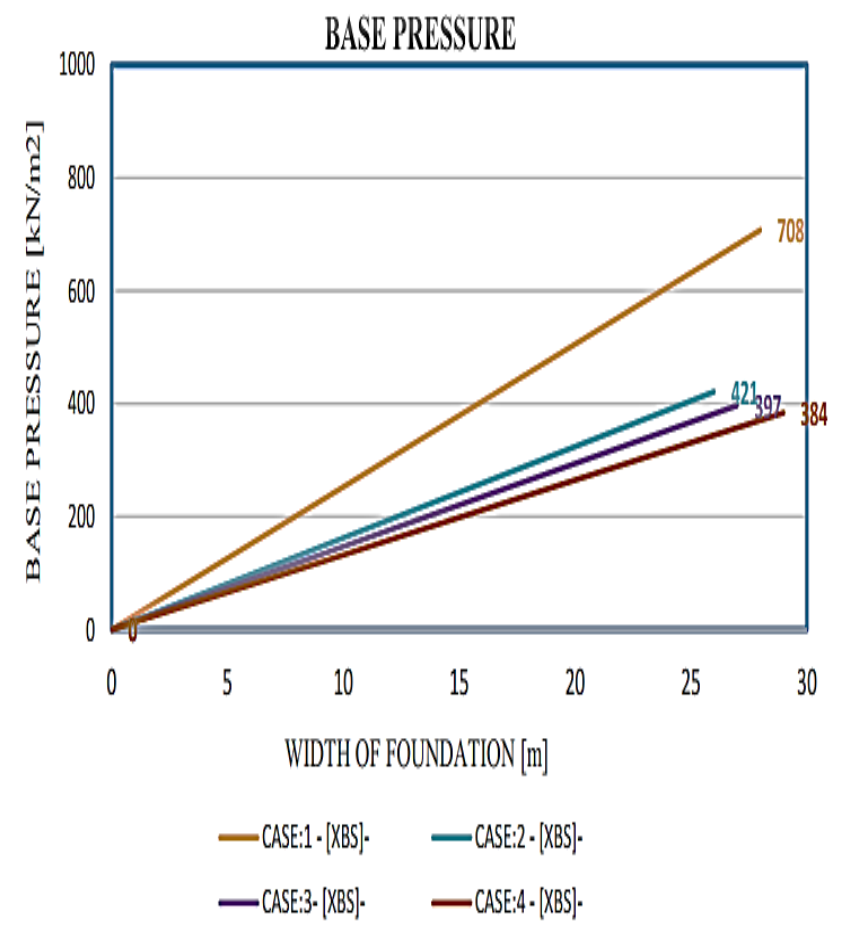

Fig: 12 Base pressure 


\subsection{Displacement of Storey}

The displacement of each storey is examined and is observed that the displacement is more for case 2 with MPS system and is less for case 1 with XBS system. This clearly indicates that the MPS system is less efficient in keeping the displacement less with 30 degrees but it is more efficient both for 45 and 60 degrees as compared to XBS system as shown in the figure 13.

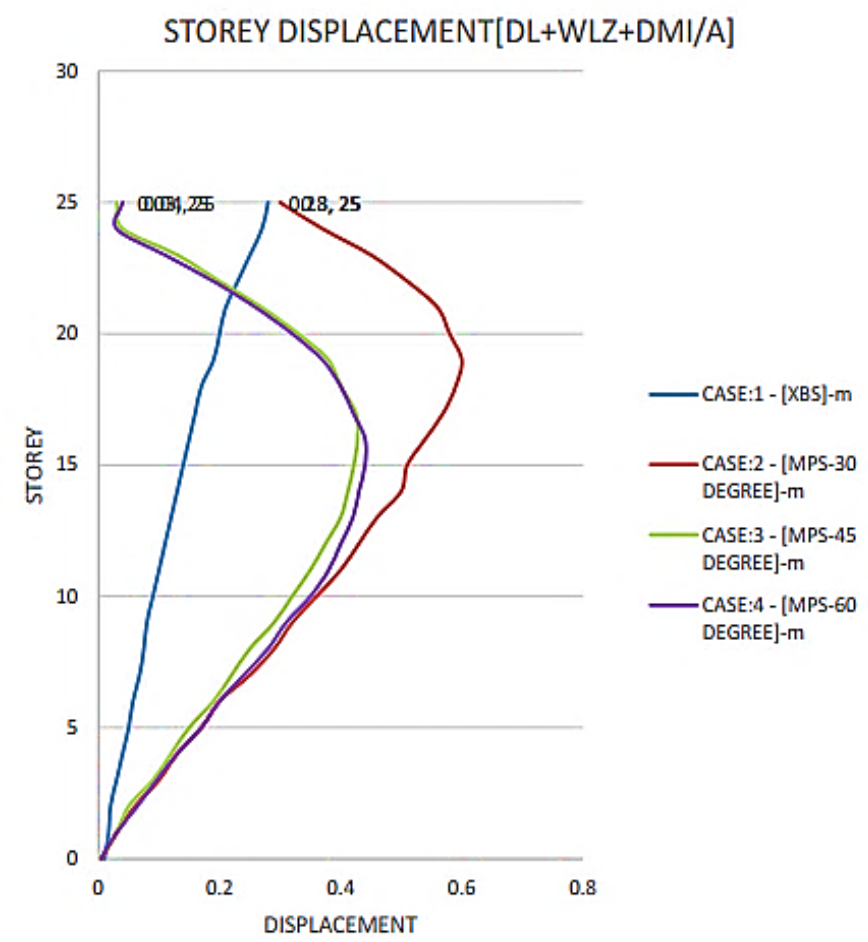

Fig: 13_story Displacement overall shear behavior of building can be significantly reduced by providing an effective mass pendulum at the top of the story irrespective of the cost of Mass Pendulum arrangement.

\section{REFERENCES}

[1] Ethiopian Building Code Of Standard, (EBCS,1995)

[2] EBCS-1 Basis of Design and Actions on Structures, Ethiopian Building Code Of Standard

[3] EBCS-3 Analysis and Design of Steel Structures, Ethiopian Building Code Of Standard

[4] AISC-ASD Steel Design Manual, 13th edition, American Institute of Steel Construction.

[5] Edwin H. Gaylord ET. al. (1992), Loads and Structures, Design of Steel Structures, 3rd Edition, McGraw Hill Inc.

[6] American Institute of Steel Construction (1986), Load and Resistance Factor Design, AISC, Chicago.

[7] ArcelorMittal Technical Brochure, Earthquake Resistant Steel Structures, Long Carbon Europe Sections and Merchant Bars, Europe.

[8] EN 1998-1:2004, Design of Structures for Earthquake Resistance, Part 1: General Rules, Seismic Actions and Rules for Buildings, (Euro code 8), CEN, European.

[9] EN 1993-1-1 (1993), "Euro code 3: Design of Steel Structures."

[10] Ronald O. Hamburger, R.O. (November 2009), Earthquakes and Seismic Design, AISC.

[11] 2009, American Institute of Steel Construction, Washington, DC.

[12] Schueller, W. (1986), High-Rise Building Structure (2nd end), Malabar, Florida: Krieger.

\section{CONCLUSION}

In the present study, high rise steel building is analyzed with XBS system (old system) and MPS system (new system) in order to evaluate the steel and concrete quantity, bending behavior, shear behavior, base pressure and displacement. The data considered for the above study is analyzed by both the methods of XBS and MPS systems with four cases. Case 1 is considered for XBS system and other cases are considered for MPS system in the analysis. The various graphs are developed for different behaviors. It is concluded that MPS system with cases 2 to 4 is giving efficient results for all the behaviors of high rise steel building as compared to XBS system, except in case of displacement behavior for 30 degree angle as shown in the figure 13. The efficiency is again more with MPS system for case 3 and case 4 with 45 and 60 degree angle as compared to XBS system. This clearly indicates that MPS system will give good results for displacement with more than 45 degree angle.

On comparision of both the methods, it is finally concluded that the behavior analysis for high rise steel buildings is more appropriate with MPS system as compared to XBS system. decrease after the application of In general, the total construction cost of the building and general stresses developed like base pressure, base bending moment and the 